\title{
A propaganda política no Facebook: \\ O uso das fanpages pelos principais candidatos à Prefeitura de Belo Horizonte
}

Resumo: $O$ artigo traz uma análise da inserção das redes sociais nas campanhas eleitorais em 2016, tomando como objeto de estudo as fanpages dos principais candidatos à disputa pela Prefeitura de Belo Horizonte. Discute-se a relação simbiótica entre mídia e política e o impacto das mídias digitais nas disputas eleitorais. Foi realizada análise de conteúdo, a partir do recorte do primeiro turno de campanha, acionando as categorias conteúdo das fanpages e formatos utilizados.

Palavras-chave: Comunicação Política. Democracia Digital. Eleição Municipal.

\section{La propaganda política en Facebook: El uso de las fanpages por los principales candidatos al Ayuntamiento de Belo Horizonte}

Resumen: El artículo presenta un análisis de la integración de las redes sociales en las campañas electorales en 2016, tomando como objeto de estudio las fanpages de los principales candidatos a concurso para la ciudad de Belo Horizonte. Se discute la relación simbiótica entre los medios y la política, y el impacto de los medios digitales en las elecciones. El análisis de contenido se realizó a partir del corte de la primera campaña redonda, activación de categorías de contenido y formatos utilizados fanpages.

Palabras clave: Comunicación Política. Democracia digital. Elección municipal.

\section{The political propaganda on Facebook: The use of fanpages by the main runners for Belo Horizonte City Hall}

\begin{abstract}
The article presents an analysis of the insertion of social networks in the electoral campaigns in 2016, taking as object of study the fanpages of the main candidates for the contest by the Belo Horizonte City Mayor. It discusses the symbiotic relationship between media and politics and the
\end{abstract}

Carla Montuori Fernandes ${ }^{1}$

Luiz Ademir de Oliveira ${ }^{2}$

Vinícius Borges Gomes ${ }^{3}$

Déborah Luísa Vieira dos Santos ${ }^{4}$

\begin{abstract}
${ }^{1}$ Doutora e Pós-Doutora em Ciências Sociais, com ênfase em Comunicação Política pela Pontifícia Universidade Católica de São Paulo (PUC-SP). É docente do Programa de Pós-Graduação em Comunicação da Universidade Paulista (UNIP);

2 Mestre e Doutor em Ciência Política pelo IUPERJ, mestre em Comunicação Social pela UFMG, atualmente é docente e pesquisador do Programa de Pós-Graduação em Comunicação Social (PPGCOM) da Universidade Federal de Juiz de Fora (UFJF) e do curso de Comunicação Social da Universidade Federal de São João del-Rei (UFSJ).

Mestrando em Comunicação Social pelo Programa de Pós-Graduação em Comunicação Social (PPGCOM) da UFJF e Graduado em

Comunicação Social - Jornalismo pela UFSJ

4 Graduanda em Comunicação Social - Jornalismo pela UFSJ e Bolsista do Programa de Bolsas de Iniciação Científica (PIBIC/FAPEMIG/UFSJ).
\end{abstract}


impact of digital media in electoral disputes. Content analysis was performed, from the cut of the first campaign shift, triggering the categories content of the fanpages and formats used.

Keywords: Political Communication. Digital Democracy. Municipal Election.

\section{Introdução}

Em Belo Horizonte, assim como em outras capitais e cidades brasileiras, o Partido dos Trabalhadores ficou fora da disputa no segundo turno nas eleições municipais de 2016, supostamente em função do desgaste envolvendo os escândalos de corrupção da Operação Lava Jato e a própria perda de apoio político, após permanecer 13 anos no governo federal. Entretanto, o cenário eleitoral foi bem diferente dos pleitos anteriores, em que a disputa esteve entre partidos que tinham uma trajetória de vitórias na capital mineira, a saber: PT, PSDB, PSB e PMDB.

Depois de oito anos de gestão do socialista Márcio Lacerda (PSB), a eleição de 2016 trouxe uma ruptura da aliança da base aliada. Com isso, a disputa tornou-se imprevisível, com 11 candidatos, sendo sete da base de apoio do então prefeito Márcio Lacerda (PSB). As sete candidaturas resultantes da ruptura na base do socialista foram: João Leite (PSDB), Délio Malheiros (PSD), Alexandre Kalil (PHS), Marcelo Álvaro (PR), Sargento Rodrigues (PDT), Eros Biondini (PROS) e Luís Tibé (PT do B). Do lado da oposição, PT e PMDB, que são aliados no plano estadual, lançaram candidatos próprios, mas que não emplacaram - o deputado Reginaldo Lopes (PT, PC do B) e Rodrigo Pacheco (PMDB). Foram lançadas ainda Maria da Consolação (PSOL) e Vanessa Portugal (PSTU).

As pesquisas de opinião pública no primeiro turno apontavam inicialmente o favoritismo de João Leite (PSDB), sendo que os demais candidatos apareciam bem distantes ${ }^{5}$. Mas, a partir de setembro, Alexandre Kalil (PHS) começou a crescer e a ameaçar o favoritismo do candidato tucano ${ }^{6}$. O resultado no primeiro turno mostrou uma disputa imprevisível: João Leite (PSDB), com 395.952 votos (33,40\%), seguido de Alexandre Kalil (PHS), com 314.845 votos (26,56\%). Os dois disputaram o segundo turno. Em terceiro lugar, apareceu Rodrigo Pacheco (PMDB), com 118.772 votos $(10,02 \%)$ e em quarto o deputado federal Reginaldo Lopes com 86.234 votos $(7,27 \%)$. No segundo turno, com uma reviravolta, Alexandre Kalil, que se lançou como outsider da política, assim como João Doria Jr. em São Paulo, conseguiu derrotar João Leite. O candidato do PHS obteve 628.050 votos $(52,98 \%)$ contra $557.356(47,02 \%)$ do tucano.

Se o cenário político e eleitoral foi impactado pela descrença nos partidos e políticos tradicionais, em função dos casos de corrupção e da crise política e institucional que o país vivenciava, a propaganda política também sofreu alterações. A promulgação da Lei 13.165/2015, que definiu as regras para as eleições de 2016, afetou a hegemonia da mídia massiva (TV e rádio) e
${ }^{5}$ Segundo pesquisa divulgada pelo IBOPE, em 22 de agosto de 2016, João Leite aparece em primeiro com $21 \%$ das intenções de voto, seguido por Alexandre Kalil com 11\%. Disponível em: https://www. eleicoes2016.com.br/pesquisa-eleitoral-belo-horizonte/. Acesso em: 03 mai. 2017.

${ }^{6}$ Segundo pesquisa divulgada pelo Datafolha, em 22 de setembro de 2016, o candidato João Leite possuía $33 \%$ das intenções de voto e Alexandre Kalil somava 21\%. Disponível em: https://www.eleicoes2016.com. br/pesquisa-eleitoral-belo-horizonte/. Acesso em: 03 mai. 2017. 


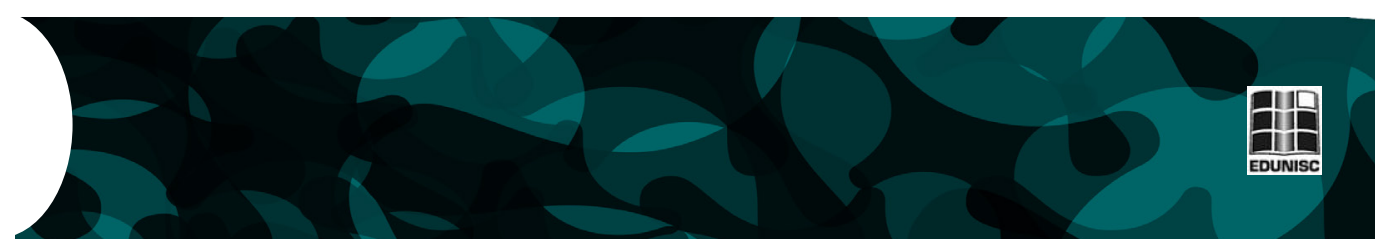

do Horário Gratuito de Propaganda Eleitoral (HGPE). Com a nova legislação, a campanha na TV e no rádio caiu de 45 para 35 dias, começando somente no dia 26 de agosto de 2016. A quantidade de minutos de cada programa foi reduzida pela metade. Com um grande número de candidatos, o tempo no HGPE foi bastante fragmentado. Com a mudança na legislação eleitoral, o trabalho de marketing e de comunicação política foi prejudicado. Com a nova legislação eleitoral, houve também mudança no financiamento de campanhas, já que as empresas foram impedidas de fazer doações aos candidatos.

Com recursos bem reduzidos e uma campanha curta na mídia massiva, os candidatos tiveram que investir na internet e nas redes sociais para estabelecer estratégias e manter o contato com o eleitorado. Se as disputas eleitorais tradicionalmente trazem uma discussão de retóricas entre situação versus oposição (Figueiredo et al, 1998), em 2016, atrelado a esta variável, ficou evidente um confronto entre os que se intitulavam outsiders da política em contraponto aos partidos e candidatos com uma trajetória consolidada em termos de carreira política, fato que se evidenciou na campanha de João Doria Jr. em São Paulo, mesmo sendo do PSDB, e Alexandre Kalil (PHS), em Belo Horizonte. Entretanto, acredita-se que o surgimento de candidatos com perfil "apolítico" esteja relacionado à crise política e institucional decorrente da Operação Lava Jato, das denúncias de corrupção e do processo de impeachment da ex-presidente Dilma Rousseff (PT).

Neste cenário de crise institucional e de mudanças nas regras eleitorais, que reduziram o impacto da mídia massiva nas estratégias de marketing eleitoral, a internet ganhou força. Conforme explicam Marques e Souza (2016), a maior variedade de suportes de comunicação expandiu o alcance da disputa eleitoral, fazendo com que a televisão passasse a compartilhar com outros ambientes midiáticos o palco principal dos embates políticos. "Em outras palavras, por conta de sua conveniência, a comunicação digital passou a ser utilizada com maior frequência para a repercussão de ideias, programas e ataques políticos' (MARQUES; SOUSA, 2016, p.183).

Nesse sentido, o artigo traz uma discussão sobre a relação simbiótica entre mídia e política e a respeito da propaganda política direcionada para as redes sociais. O trabalho centra-se na análise do conteúdo e do formato das fanpages dos quatro principais candidatos (Alexandre Kalil, João Leite, Rodrigo Pacheco e Reginaldo Lopes), tomando como base o primeiro turno de campanha, que compreendeu o período de 16 de agosto a 30 de setembro de 2016. Foram analisados os conteúdos mais acionados pelos candidatos e os formatos mais utilizados.

\section{A relação simbiótica entre o campo da Política e a esfera da Comunicação}

Como os partidos e líderes políticos têm utilizado estrategicamente a arena midiática, é importante tecer considerações acerca das relações entre 

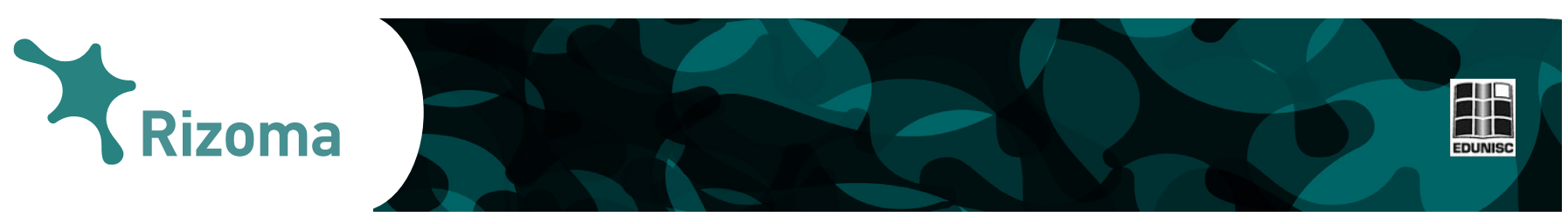

mídia e política. Em função do ainda extenso alcance dos meios tradicionais e da popularização dos novos dispositivos tecnológicos, é necessário reconhecer que se vive em meio a um bios midiático que organiza e estrutura a contemporaneidade. Os atores políticos utilizam o poder do campo midiático para enfatizar seus discursos e incorporam as lógicas e gramáticas comunicacionais ao próprio funcionamento da política, que leva a um crescente personalismo. Os meios de comunicação massivos e digitais desempenham papel fundamental na contemporaneidade para que os atores políticos ganhem visibilidade. Em relação à política, os mass media alteram as formas do discurso, a relação entre representantes e representados e até as vias de acesso para a carreira pública. Eles utilizam dos recursos do marketing político para conquistar o eleitorado. Dessa forma, pode-se dizer que a mídia funciona como palco para as disputas políticas. (GOMES, 2004; RODRIGUES, 1990).

As campanhas, no entanto, exigem uma profissionalização cada vez maior tanto das ações de comunicação como de marketing eleitoral. Em consequência, tem-se uma tendência cada vez maior ao personalismo. Verifica-se um processo de espetacularização da política propiciada pela adaptação do discurso político à gramática dos meios de comunicação, sejam eles massivos ou digitais. De acordo com Gomes (2004), a mídia aciona uma dimensão espetacular. Não se trata de um mero instrumento de informação, mas um meio de exposição de atores, de serviços e produtos. Ao discutir conceitos de espetacularização e encenação, Gomes (2004) disserta que a política é um show e um espetáculo para o consumo dos espectadores. Nesse contexto, recorrendo à metáfora teatral, o autor aponta que os papéis são planejados e devem ser levadas em conta variáveis como bastidores, cenas, plateia, figurino, atores, luzes, cenários etc.

Diversos autores apontam que as eleições vêm sendo disputadas sobre uma crescente ênfase nos candidatos, explorando atributos pessoais, administrativos e políticos como estratégia de comunicação política e não mais nos partidos políticos. Manin (1995) afirma que a democracia de partido dá lugar hoje à democracia de público, centrada nos líderes personalistas e no crescente papel dos meios de comunicação. Ele afirma que os candidatos precisam se tornar eficientes comunicadores por estarem em permanente contato via mídia com o seu eleitorado. A escolha ocorre em função de atributos pessoais e as preferências partidárias ficam em segundo plano.

\section{Propaganda política e as campanhas eleitorais na internet}

Quanto às disputas políticas e eleitorais, Figueiredo et al. (1998) afirmam que há uma disputa de retórica entre o discurso da situação versus o discurso da oposição. Os autores explicam que a retórica política é de natureza ficcional. Tal distinção explica-se devido ao fato de que a retórica política passa por uma interpretação do mundo, que é de natureza ficcional, voltada para percepções sobre o real. Num debate político e eleitoral, com 
objetivo de convencer os eleitores, os atores políticos constroem um mundo atual possível, igual ou pouco diferente do mundo atual real, e com base nele projetam um novo e bom mundo futuro possível. A argumentação tem duas vertentes: (1) o mundo atual está ruim, mas ficará bom ou (2) o mundo atual está bom e ficará ainda melhor. A primeira vertente refere-se à argumentação da oposição; e a segunda, da situação.

Se a mídia passa a ser central para os campos sociais, hoje se discute não somente o poder dos meios de comunicação massivos, mas a comunicação digital, cada vez mais inserida no cotidiano dos brasileiros. Gomes (2011) discute a democracia digital atrelando à questão dos dilemas da participação política nos regimes democráticos representativos. $\mathrm{O}$ autor argumenta que a democracia digital também esbarra nos obstáculos de criar incentivos para que o cidadão seja efetivamente participativo. A democracia digital pode incrementar os mecanismos de participação, mas depende de incrementos à participação popular e à consolidação da democracia.

Entendo por democracia digital qualquer forma de emprego de dispositivos (computadores, celulares, smartphones, palmtops, ipads...), aplicativos (programas) e ferramentas (fóruns, sites, redes sociais, medias sociais...) de tecnologias digitais de comunicação para suplementar, reforçar ou corrigir aspectos das práticas políticas e sociais do Estado e dos cidadãos em benefício do teor democrático da comunidade política. (GOMES, 2011, p. 28).

Se a democracia digital possibilita novas formas de interação e de participação política, destacam-se os investimentos cada vez maiores em ferramentas como as redes sociais, como é o caso do Facebook nas disputas eleitorais. Ao discutir as redes sociais, Recuero (2009) aponta como a comunicação mediada pelo computador foi capaz de gerar uma mudança profunda nas formas de organização, identidade, conversação e mobilização social. Mais do que permitir a comunicação dos indivíduos, essas novas redes ampliaram a capacidade de conexão dos sujeitos, pois elas não só conectam computador, como também pessoas.

Aggio (2013) discute o uso das plataformas da internet nas campanhas eleitorais como uma estratégia relativamente recente nas democracias contemporâneas, que teve início na década de 90 em campanhas nos Estados Unidos. Mas somente no século XXI com o potencial da web 2.0 que as estratégias de campanhas passaram a explorar questões que são próprias da internet, como a interação, a participação em tempo real e a convergência de mídia. $\mathrm{O}$ autor destaca quatro pontos-chaves na sua análise da internet e o seu uso em estratégias de campanhas eleitorais: (a) o fornecimento e informações não mediadas pelos media noticiosos; (b) paridade de disputas entre campanhas de pequeno e grande porte, que não é do interesse do pesquisador estabelecer comparações, até porque a criação de websites, fanpages, entre outras plataformas da web tornam-se de fácil acesso a qualquer candidato; (c) interatividade - que é a possibilidade de criar ambientes em que possa haver a interação entre eleitores e, eventualmente, entre eleitores 

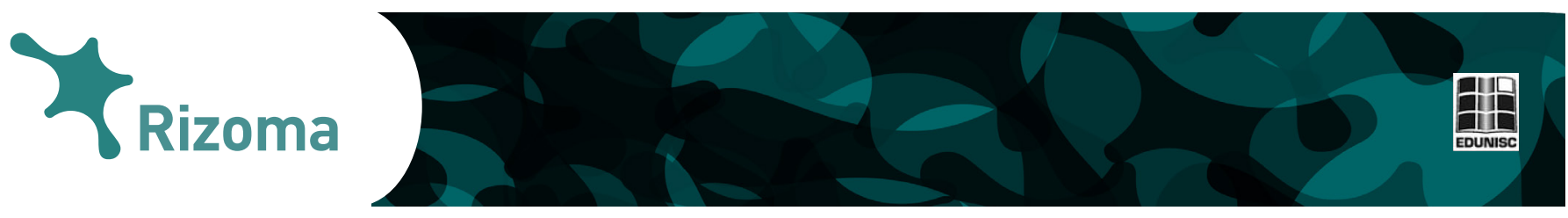

e os candidatos; (d) ativismo - recursos que possibilitem novas formas de ativismo nas campanhas. Sobre as diferenças entre a campanha na web e nos meios massivos, Aggio (2013) traça alguns pontos importantes.

\begin{abstract}
A grande diferença entre a televisão, o rádio e a Internet, então, estaria na forma de interação e de participação que a última oferece. Ao passo que os dois primeiros têm objetivos específicos claros de construir imagens e passar com eficiência uma mensagem e prescindir de contatos diretos, interativos, a terceira proporciona uma maior aproximação da campanha ao possibilitar a troca de mensagens, produzindo um efeito de sentimento de pertença e configurando elementos de participação. Se, por um lado, os novos mecanismos de participação servem às estratégias de fidelização prescritas pelo marketing político, por outro lado há práticas que podem assegurar que as interferências e sugestões dos cidadãos de fato sejam levadas em consideração. Invariavelmente, nesta circunstância, não há possibilidade de dissociar o que seria da ordem do marketing político e o que seria da ordem de uma diferenciação do modo de fazer campanha com reflexos do incremento à democracia. (AGGIO, 2013, p. 180).
\end{abstract}

Nessa perspectiva, Rossini e Leal (2013) argumentam que, em grande medida, os candidatos não buscam a interação, pois têm o receio de serem questionados pelos eleitores sobre questões polêmicas da campanha. Mas precisam recorrer às mídias digitais como espaços cada vez mais importantes em termos de estratégia eleitoral, a fim de maximizar votos. Apesar de se tornarem mais efetivas somente em 2016, nas eleições de 2010, o Twitter já tinha sido bastante acionado pelos candidatos na disputa presidencial.

\title{
4. Análise das estratégias dos candidatos à Prefeitura de Belo Horizonte nas fanpages
}

Como procedimentos metodológicos, o artigo utilizou, primeiramente, a pesquisa bibliográfica. Outra ferramenta usada foi a pesquisa documental, com a coleta das postagens nas páginas dos candidatos no Facebook fanpages. $\mathrm{O}$ recorte foi feito com base nos quatro candidatos com maior votação no primeiro turno: João Leite (PSDB), Alexandre Kalil (PHS), Rodrigo Pacheco (PMDB) e Reginaldo Lopes (PT).

Para analisar as estratégias dos candidatos à Prefeitura de Belo Horizonte foram coletadas as postagens dos candidatos em suas respectivas fanpages, durante o primeiro turno. Essa coleta pode ser feita a partir do "Print Screem", recurso que captura a imagem presente na tela do computador. O período escolhido para análise das postagens compreendeu o início das campanhas eleitorais, em 16 de agosto de 2016 até o seu último dia, em 30 de setembro de 2016.

Com o material coletado, utilizou-se a análise de conteúdo (BARDIN, 2010). A primeira categoria diz respeito aos conteúdos utilizados pelos candidatos no Facebook. Os segmentos foram divididos em segmentos de campanha e metacampanha (ALBUQUERQUE, 1999). Quanto às categorias 
de campanha (que se referem a conteúdo político), são: (1) Alteração na foto de perfil/capa; (2) Imagem do candidato; (3) Construção da Imagem da Cidade; (4) Desconstrução da Imagem da Cidade; (5) Temas políticos saúde, educação, mobilidade urbana, segurança pública, emprego e geração de renda, políticas sociais, esporte, cultura e lazer, habitação, orçamento participativo, animais, minorias, cardápio e outros; (6) Conjuntura Política; (7) Fatos Contemporâneos; (8) Ataque aos Adversários; (9) Menção a Partidos. Quanto a categorias de metacampanha, são: (1) Cenas de Campanha - divididas em 1.1 Atividades de campanha (panfletagem, carreata e outros), 1.2 Debate, 1.3 Balanço do dia/campanha, 1.4 Entrevista na mídia; (2) Apoio e agradecimento de líder político, populares, personalidades; (3) Agenda; (4) Pesquisa de Opinião Pública; (5) Mobilização e Apelo ao Engajamento dos Eleitores; (6) Pedagogia do Voto; (7) Outros.

Quanto ao formato ou recursos da web utilizados, as categorias são: (1) Fotos; (2) Gráficos; (3) Charges; (4) Vídeos; (5) Áudios; (6) Ilustrações/ Imagens; (7) Links; (8) Evento; (9) GIF; (10) Check-In; (11) Outros.

Quanto ao contexto político da disputa de Belo Horizonte, houve períodos de polarização entre frente de esquerda versus frente de direita. Passou pelo inusitado acordo entre PT e PSDB em 2008, que elegeu Márcio Lacerda e desencadeou na grande fragmentação em 2016, com 11 candidatos.

Em 1988, o cenário começou favorável ao PSDB, que elegeu Pimenta da Veiga, tendo como vice Eduardo Azeredo. Tendo sido derrotado em 1990 para o governo de Estado, Pimenta da Veiga desistiu de retornar ao cargo de prefeito e Azeredo assumiu definitivamente. Em 1992, o PT emplacou Patrus Ananias derrotando Maurício Campos (PFL), Sérgio Ferrara (PMDB) e Aécio Neves (PSDB). Em 1996, houve um racha na esquerda entre Virgílio Guimarães (PT) e Célio de Castro (PSB), que saiu vitorioso derrotando o petista. Em 2000, a esquerda aliou-se novamente e reelegeu-se Célio.

Em 2001, Célio filiou-se ao PT, mas sua carreira política foi interrompida por um AVC, em 8 de novembro de 2001. Então, o vice Fernando Pimentel (PT) assumiu e concorreu à Prefeitura em 2004 pelo PT. A frente de esquerda derrotou novamente o PSDB, que tinha como candidato João Leite. Pimentel, que tinha altos índices de aprovação, ganhou no primeiro turno, com $70 \%$ dos votos.

Em 2008, uma aliança inusitada marcou a disputa pela Prefeitura de Belo Horizonte. Fernando Pimentel (PT) fechou um acordo com o então governador Aécio Neves (PSDB) de lançar um candidato de união - o secretário estadual de Desenvolvimento Econômico, Márcio Lacerda (PSB). Sem qualquer projeção política, Lacerda tinha bom trânsito entre os petistas e tucanos. A aliança foi considerada polêmica por agregar duas forças partidárias antagônicas, tanto no cenário estadual como nacional. Tanto Pimentel como Aécio argumentavam que se tratava de um exemplo da política mineira - a de serem conciliadores e conseguirem buscar o consenso mesmo quando estão em campos de disputa, a chamada cultura da mineiridade. O candidato socialista saiu vitorioso, derrotando Leonardo Quintão (PMDB) na época que cresceu e se tornou um fenômeno eleitoral, 
disputando o segundo turno. Em 2012, Lacerda lançou-se novamente candidato à reeleição com apoio do PSDB, mas enfrentou Patrus (PT). O socialista venceu pela segunda vez.

No entanto, em seu segundo mandato, Lacerda perdeu popularidade. Com o desgaste do seu governo, houve uma ruptura da base de apoio ao PSB. Conforme mencionado anteriormente, da base de apoio de Márcio Lacerda, houve uma grande divisão, que propiciou o lançamento de sete candidatos à disputa pela Prefeitura de BH. O PSDB rompeu aliança com o PSB e lançou João Leite (PSDB/PPS/DEM/PRB e PRTB). O tucano elegeu-se deputado estadual em 1994 e está no seu sexto mandato na Assembleia Legislativa. Disputou a Prefeitura em 2000 e 2004, mas foi derrotado. Décio Malheiros (PSD/PSB) que foi vice-prefeito de Lacerda, foi vereador em Belo Horizonte e eleito duas vezes deputado estadual por Minas Gerais.

O empresário Alexandre Kalil (PHS/PV), do ramo de engenharia, que se tornou conhecido por ser presidente do Clube Atlético Mineiro, chegouse a filiar ao PSB em 2014 para concorrer a deputado federal, mas desistiu e migrou para o PHS. Na campanha, intitulou-se como empresário e outsider da política, com uma campanha bem ofensiva em relação aos adversários. Bem distante de João Leite nas pesquisas, conseguiu alcançá-lo, ir para o segundo turno e vencer a disputa. Da base de apoio de Márcio Lacerda, surgiu também a candidatura de Eros Biondini (PROS), que se elegeu deputado federal em 2010, e se tornou secretário de Estado de Esportes do governo Antônio Anastasia (PSDB) no ano de 2013. Filiou-se ao PROS para disputar a sucessão municipal.

Outro dissidente da situação foi o Sargento Rodrigues (PDT/PTB). Policial militar, a sua carreira política começou ao se eleger deputado estadual pelo PL, em 1998. Mudou-se para o PDT e reelegeu-se deputado estadual em 2002, 2006, 2010 e 2014, estando no seu quinto mandato. O PR também lançou candidatura própria à sucessão municipal com o empresário Marcelo Álvaro Antônio (PR/PSDC). Apoiado por uma frente de partidos nanicos, Luis Tibé (PT do B/PRP/PSL/PTC/PEN/PPL/PMB) lançou-se candidato a prefeito, depois de se eleger vereador em 2008 e sair vitorioso na disputa por uma vaga de deputado federal em 2010 e 2014.

Do lado da oposição, saíram quatro candidatos. O deputado federal Reginaldo Lopes (PT/PC do B) teve como candidata a vice, Jô Moraes, do PC do B. Em seu quarto mandato de deputado federal (2002, 2006, 2010 e 2014), Reginaldo foi o deputado mais votado em Minas em 2014, com mais de 300 mil votos. O PMDB rompeu aliança com o PT e lançou Rodrigo Pacheco (PMDB/PSC/PTN), que é advogado e ganhou a eleição para deputado federal em 2014. A professora e sindicalista Vanessa Portugal (PSTU) disputou a Prefeitura da capital mineira pela terceira vez (2002, 2012 e 2016). Professora e líder de movimentos sociais, Maria da Consolação (PSOL/PCB) foi outro nome que representa a esquerda na disputa pela sucessão de Márcio Lacerda. 


\section{YRizoma}

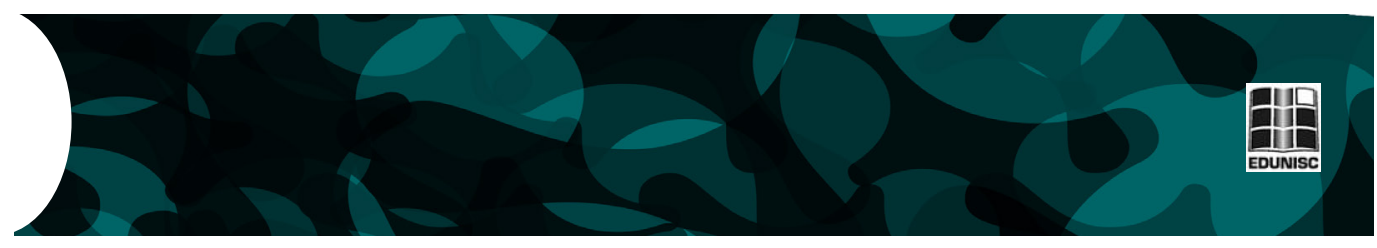

\subsection{Análise de Conteúdo: as estratégias dos candidatos nas fanpages}

Para o estudo, foram analisadas as postagens do $1^{\circ}$ turno das eleições municipais de Belo Horizonte, dos candidatos João Leite, Alexandre Kalil, Rodrigo Pacheco e Reginaldo Lopes. Foram analisadas duas categorias: conteúdo e formato das postagens.

\subsubsection{Conteúdo das fanpages}

O candidato João Leite (PSDB) realizou 285 publicações em sua fanpage, sendo uma média de 6 postagens por dia. Quanto ao conteúdo das postagens, os três temas predominantes foram: "Imagem do candidato" presente em 54 publicações (19\%), seguido de "Atividades de campanha" com 52 postagens (18\%) e "Mobilização e apelo ao engajamento dos eleitores" com 25 postagens ( $9 \%$ das postagens). Quanto aos temas políticos, o candidato mostrou-se sem foco, já que optou por abordar uma grande diversidade de assuntos, com poucas postagens para cada área - saúde, educação, mobilidade urbana, políticas sociais, entre outras. O tema que obteve maior número de postagens na página do candidato foi "Saúde", com 16 publicações $(5,6 \%)$. Durante o período de campanha, é possível constatar que ocorreu a falta de uma estratégia que definisse as temáticas prioritárias do candidato nas redes sociais. $\mathrm{O}$ candidato tucano também postou mensagens de cumprimento aos seguidores juntamente com fotos de Belo Horizonte, seja retirada para a campanha ou enviada pelos próprios seguidores, visando a aproximar ainda mais a relação entre candidato e eleitores. Isso mostra a tentativa de buscar adequar-se à lógica da internet, ou seja, da gramática das mídias digitais.

O segundo colocado, Alexandre Kalil (PHS), foi o candidato que menos investiu em publicações em sua fanpage, com apenas 63 postagens no período analisado, uma média de 1,4 publicações por dia. Os conteúdos mais utilizados foram: em $1^{\circ}$ "Imagem do candidato" e "Mobilização e apelo ao engajamento dos eleitores", com 8 postagens para cada tema (13\%), seguido de "Desconstrução da imagem da cidade" e "Pesquisa de intenção de voto", com 7 postagens cada tema (11\%). Já o tema "Ataque aos Adversários' obteve 6 postagens (10\%). Observa-se que a campanha de Kalil contou com um tom mais agressivo, já que "Desconstrução da imagem do candidato" e "Ataque aos Adversários" somaram 13 postagens, tornando a propaganda negativa como sua estratégia predominante. Tal estratégia supostamente esteve alinhada à construção da sua imagem como "apolítico", que questionava os partidos e candidatos, classificando-os como tradicionais e profissionais da política.

O terceiro colocado no $1^{\circ}$ turno, Rodrigo Pacheco (PMDB), fez 529 publicações em sua fanpage, sendo uma média de 11 postagens por dia. 
Os conteúdos mais acessados foram: "Atividades de campanha", com 91 publicações (17\%), seguido de segmentos de metacampanha - "Debate", com 49 postagens (9\%), "Apoio e Agradecimentos de Líderes Políticos, Personalidades e Populares", com 7 postagens (8,8\%). Além disso, a categoria "Outros", com aproximadamente 5\% do total das postagens, inclui postagens com "jingles", o quadro "prefeito por um dia", uma abertura para as demandas da população belo-horizontina, e as propostas inspiradas nas ações bemsucedidas implantadas em Medellín, na Colômbia. Vale ressaltar ainda que o candidato peemedebista foi o que melhor distribuiu os conteúdos de suas postagens, abordando temáticas diversas. Pacheco fez uso intensivo das redes sociais, porém dedicou pouco tempo para construção da sua imagem e da própria campanha, já que foram postadas poucas mensagens referentes ao candidato, com apenas 30 publicações, um total de $6 \%$ do conteúdo.

O quarto candidato, Reginaldo Lopes (PT), teve um total de 603 postagens, sendo uma média de 13 postagens por dia. O petista foi o candidato que mais fez publicações no primeiro turno da campanha. Os conteúdos mais acessados foram: "Atividades de campanha", com 119 publicações (20\%), seguido de "Fatos Contemporâneos", com 81 postagens (13\%), "Atividades de Campanha", com 66 publicações (11\%) e "Imagem do Candidato", com 40 postagens $(7 \%)$. O candidato teve como estratégia passar a imagem de uma campanha muito dinâmica com atividades e eventos. No entanto, a maior parte das ações girava em torno de visita do candidato a bairros da cidade e encontros com eleitores. Isso revela um descompasso entre o que se procurou construir no universo virtual e o que, de fato, estava ocorrendo na campanha, que não empolgou os eleitores e, principalmente, a militância do PT. Da mesma forma, o candidato investiu pouco na construção da sua imagem, já que, mesmo tendo sido o deputado mais votado em 2014, teve uma votação muito espalhada em Minas Gerais e não era um nome tão conhecido pelo eleitorado belo-horizontino.

No que diz respeito à categoria "Mobilização e apelo ao engajamento dos eleitores", é interessante destacar as ações realizadas por Reginaldo Lopes, já que o candidato usou a fanpage para incentivar o eleitor com contribuições para melhorar a cidade de Belo Horizonte, como também chamou os internautas para contribuir com doações de dinheiro durante a campanha, já que a nova legislação eleitoral proíbe doações de empresas. Novamente, esbarrou na dificuldade em relação à consolidação de sua candidatura. Mesmo com a força do PT em Belo Horizonte, as pesquisas no primeiro turno apontavam o candidato com menos de $5 \%$ das intenções de voto. A categoria "Fatos Contemporâneos" foi muito acionada pelo candidato petista, por conta do impeachment da ex-presidente Dilma Rousseff (PT) e dos movimentos "Fora Temer", que eram contrários à permanência do então presidente Michel Temer (PMDB) no poder.

A primeira categoria de análise é a de conteúdo das postagens. O Quadro 1 traz o conteúdo das postagens no primeiro turno de campanha dos quatro candidatos. 


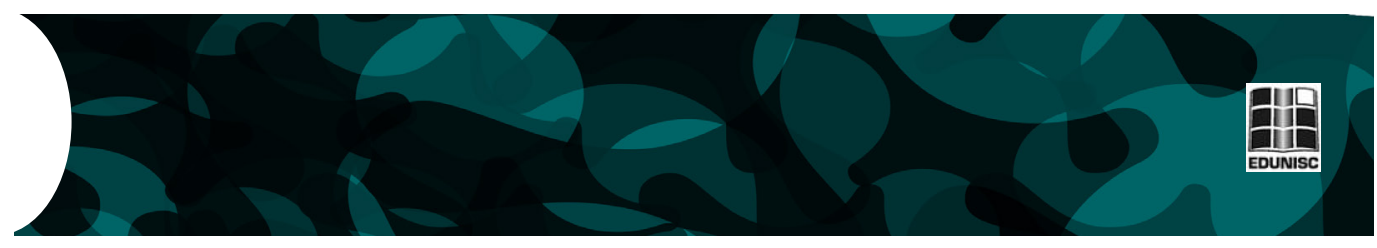

Quadro 1 - Conteúdo das postagens no primeiro turno da campanha

\begin{tabular}{|c|c|c|c|c|c|}
\hline Candidato / conteúdo & $\begin{array}{l}\text { João Leite } \\
\text { (PSDB) }\end{array}$ & $\begin{array}{l}\text { Alexandre } \\
\text { Kalil (PHS) }\end{array}$ & $\begin{array}{l}\text { Rodrigo } \\
\text { Pacheco } \\
\text { (PMDB) }\end{array}$ & $\begin{array}{l}\text { Reginaldo } \\
\text { Lopes (PT) }\end{array}$ & Total \\
\hline Atualização de foto de perfil/capa & 10 & 4 & 7 & 8 & 29 \\
\hline Imagem do candidato & 54 & 8 & 30 & 40 & 132 \\
\hline Construção da imagem da cidade & 2 & 0 & 5 & 10 & 17 \\
\hline Desconstrução da imagem da cidade & 11 & 7 & 28 & 25 & 71 \\
\hline Temas políticos: saúde & 16 & 3 & 10 & 10 & 39 \\
\hline Temas políticos: educação & 3 & 0 & 10 & 9 & 22 \\
\hline Temas políticos: mobilidade urbana & 4 & 4 & 20 & 8 & 36 \\
\hline Temas políticos: segurança pública & 13 & 1 & 11 & 2 & 27 \\
\hline Temas políticos: emprego e geração de renda & 4 & 0 & 15 & 8 & 27 \\
\hline Temas políticos: políticas sociais & 1 & 0 & 3 & 6 & 10 \\
\hline Temas políticos: outros & 4 & 1 & 26 & 20 & 51 \\
\hline Temas políticos: cardápios & 13 & 1 & 16 & 27 & 57 \\
\hline Conjuntura política & 0 & 1 & 16 & 4 & 21 \\
\hline Ataque a adversários & 1 & 6 & 36 & 23 & 66 \\
\hline Resposta ao ataque de adversários & 0 & 0 & 2 & 1 & 3 \\
\hline Menção a partidos & 0 & 0 & 2 & 2 & 4 \\
\hline Atividades de campanha & 52 & 6 & 91 & 119 & 268 \\
\hline Debate & 14 & 3 & 49 & 33 & 99 \\
\hline Balanço do dia/campanha & 0 & 0 & 4 & 2 & 6 \\
\hline Entrevista nos meios de comunicação & 2 & 1 & 23 & 16 & 42 \\
\hline Apoio/ agradecimento de líderes, políticos e populares & 14 & 0 & 47 & 66 & 127 \\
\hline Agenda & 12 & 2 & 14 & 36 & 64 \\
\hline Pesquisa de intenção de voto & 18 & 7 & 8 & 7 & 40 \\
\hline Mobilização e apelo ao engajamento dos eleitores & 25 & 8 & 32 & 40 & 105 \\
\hline Pedagogia do voto & 0 & 0 & 2 & 0 & 2 \\
\hline Fatos contemporâneos & 6 & 0 & 5 & 81 & 92 \\
\hline Outros & 6 & 0 & 20 & 0 & 23 \\
\hline TOTAL & 285 & 63 & 529 & 603 & 1480 \\
\hline
\end{tabular}

Fonte: autoria própria

Somando todas as publicações dos quatro candidatos, tem-se um total de 1.480 postagens. O expressivo número ocorre já que os conteúdos abordados pelos candidatos podem ser referir a mais de uma categoria na mesma postagem. Os conteúdos que mais apareceram, analisando os quatro candidatos mais bem votados, foram: "Atividades de campanha", com 268 postagens (18\%), "Imagem do candidato", com 132 publicações (9\%) e "Apoio/agradecimento de líderes, políticos e populares", com 105 postagens (8,5\%).

Percebe-se que a preocupação maior dos candidatos era mostrar aos seguidores das respectivas fanpages as atividades feitas ao longo da campanha, como carreatas, caminhadas pelos bairros, o contato face a face com o eleitorado, entre outras estratégias. Observa-se, conforme apontam 
Oliveira e Coimbra (2016), que, tanto nas redes sociais, como nas fanpages, até pelas características da internet (abertura de vários links pelo internauta, rapidez na veiculação dos conteúdos, pouco grau de fixação simbólica), os candidatos trabalham pouco os segmentos de campanha, como a discussão de temas políticos e priorizam os segmentos de metacampanha (que tratam do andamento da campanha). Pela instantaneidade e por acionar o eleitor em tempo real, a estratégia é divulgar assuntos que mobilizem o eleitor. Isso remete a outro uso bastante frequente das redes pelos candidatos que é o apelo ao engajamento do cidadão, para que participe da campanha, mesmo que seja no ambiente virtual, seja curtindo postagens ou compartilhando conteúdos e imagens que reforçam a imagem da candidatura ou do candidato. Observa-se também a ênfase na construção da imagem dos candidatos, que se relaciona à tendência do personalismo, em que o líder político é reconhecido por seus atributos pessoais, deixando o partido em segundo plano (MANIN, 1995).

\subsubsection{Formatos utilizados pelos candidatos}

A segunda categoria de análise é o formato utilizado. Esta categoria abrange os recursos utilizados nas postagens, sejam eles nativos ou não das redes sociais. Entre os recursos têm-se o uso de fotos, ilustrações/imagens, GIF, vídeos (podendo ser ou não de transmissões ao vivo), check-in (possibilita marcar o local em que se está ou pelo qual se passou), evento (convite a algum evento que pode ter a presença confirmada ou não), entre outros. Vários formatos foram explorados pelos candidatos, como revela o Quadro 2.

Quadro 2 - Formatos acionados pelos candidatos na primeira semana

\begin{tabular}{|c|c|c|c|c|c|}
\hline Candidato / conteúdo & $\begin{array}{l}\text { João Leite } \\
\text { (PSDB) }\end{array}$ & $\begin{array}{l}\text { Alexandre } \\
\text { Kalil (PHS) }\end{array}$ & $\begin{array}{l}\text { Rodrigo } \\
\text { Pacheco } \\
\text { (PMDB) }\end{array}$ & $\begin{array}{l}\text { Reginaldo Lopes } \\
\text { (PT) }\end{array}$ & Total \\
\hline Fotos & 40 & 19 & 144 & 130 & 333 \\
\hline Gráficos & 3 & 0 & 1 & 0 & 4 \\
\hline Charges & 0 & 0 & 0 & 0 & 0 \\
\hline Vídeos & 71 & 36 & 175 & 171 & 453 \\
\hline Áudios & 0 & 0 & 0 & 0 & 0 \\
\hline Ilustrações/Imagens & 106 & 0 & 147 & 64 & 317 \\
\hline Links & 32 & 7 & 31 & 121 & 191 \\
\hline Evento & 0 & 1 & 2 & 13 & 16 \\
\hline Check-in & 15 & 0 & 9 & 95 & 119 \\
\hline GIF & 16 & 0 & 15 & 2 & 33 \\
\hline Outros & 2 & 0 & 5 & 7 & 14 \\
\hline TOTAL & 285 & 63 & 529 & 603 & 1480 \\
\hline
\end{tabular}

Fonte: autoria própria 


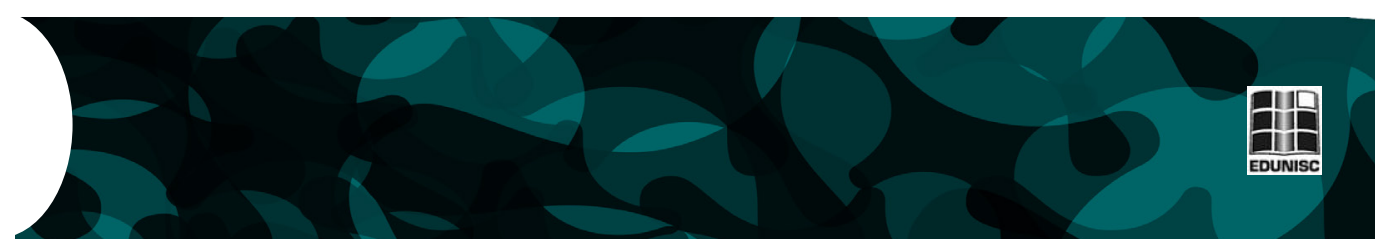

Quanto ao formato utilizado, João Leite (PSDB) recorreu mais às "Ilustrações/Imagens", já que, de um total de 285, acionou 106 postagens (37\%), seguido de "Vídeos", com 71 postagens (25\%) e "Fotos", com 40 postagens (14\%). Já Kalil(PHS), que saiu vitorioso, fez uma campanha pouco adaptada à lógica midiática e recorreu a apenas a três formatos: "Vídeos", com 36 postagens (57\%), "Fotos" com 19 postagens (30\%) e "Links", com 7 postagens (11\%). A maior parte dos vídeos focava o candidato comentando algum assunto ou tecendo críticas aos adversários, sem um trabalho de edição e de forma mais amadora, justamente para gerar a impressão de uma campanha pouco profissionalizada de um outsider da política. Rodrigo Pacheco (PMDB) recorreu mais aos vídeos em suas postagens, com 175 publicações (33\%). Em segundo lugar, ficou "Ilustrações/Imagens", com 147 postagens $(30 \%)$ e terceiro "Fotos", contabilizando um total de 144 postagens (29,3\%). Já o candidato petista, Reginaldo Lopes, utilizou mais o formato "Vídeo" (43\% das publicações ou em 171 postagens), "Fotos" (em 130 postagens ou 32\%) e "Links" (em 121 postagens ou 30\% das publicações).

No âmbito geral, os recursos mais acessados foram: "Vídeos" (presente em 30,6\% das publicações), seguido de "Fotos" (22,3\%), "Ilustrações/ imagens" (19,8\%). Entre os recursos que são disponibilizados pela internet e pelas redes sociais tiveram destaque o uso de "Links", que direcionam a páginas externas, o qual esteve presente em 13,8\% das publicações. Outro recurso bastante utilizado foi o de "Check-in", o qual o candidato marcava onde estava ou por onde havia passado ( $8,5 \%$ das publicações).

Durante a análise, foi possível identificar os esforços dos candidatos para transformar suas fanpages em um espaço mais atrativo para os eleitores e seguidores, sendo que, ao dispor desta plataforma online, é possível a utilização das mais diversas ferramentas, transformando a campanha e a divulgação de ideias e propostas mais atrativas e bem-humoradas. Além disso, há a oportunidade de a campanha ser feita em tempo real, com transmissões ao vivo, marcação dos locais onde os candidatos se encontram, por meio do "Check-in", além de permitir que os eleitores possam acompanhar os eventos promovidos pelos candidatos e confirmar participação, com uso do recurso "Evento". Conforme explica Gomes (2004), é fundamental que o discurso político, seja nas mídias massivas ou digitais, procure se adequar à lógica midiática, tornando-se espetacular - por meio da ruptura das regularidades, do caráter de entretenimento ou mesmo da dramatização.

$\mathrm{O}$ uso dos recursos tecnológicos, principalmente das redes sociais, demonstra que os candidatos estão conectados e atentos às inovações e ao mundo virtual. Isso reflete as mudanças geradas pela comunicação mediada pelo computador (RECUERO, 2009). No entanto, conforme apontaram Rossini e Leal (2013), os candidatos, até por receio de questionamentos sobre questões e decisões polêmicas, ainda utilizam as mídias digitais com restrições, valendo-se prioritariamente dos recursos como espaço estratégico de divulgação de mensagens, sem considerar as ferramentas e possibilidades de interação com o eleitor. 

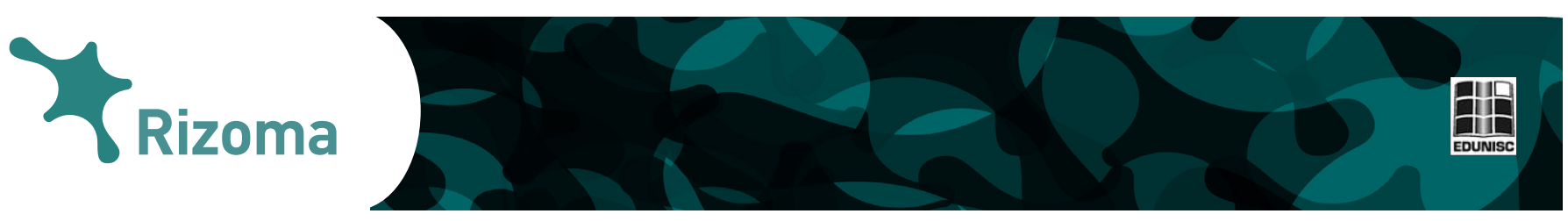

\section{Considerações finais}

Pode-se afirmar que vivenciamos uma transição nos processos comunicacionais, especificamente no uso das mídias na composição de estratégias políticas e eleitorais. Hoje, apesar da inserção que a mídia televisiva possui no Brasil, é importante apontar o uso recorrente das mídias digitais, como os dispositivos móveis. No entanto, a internet ainda tem sido pouco utilizada para discussões e debates políticos. Por isso, o uso das mídias virtuais nas campanhas eleitorais ainda não ocupa um espaço estratégico.

Nas eleições municipais de 2016 ocorreram algumas particularidades. A mudança na legislação eleitoral encolheu o período da veiculação do Horário Gratuito de Propaganda Eleitoral (HGPE), que passou de 45 para 35 dias, sendo que o tempo também foi reduzido pela metade. Com isso, os candidatos das maiores coligações, tiveram em torno de dois minutos. Alguns candidatos tiveram menos de 30 segundos. Nesse sentido, as redes sociais tornaram-se um pouco mais efetivas para os candidatos.

Entretanto, mesmo com menor peso das mídias massivas, observa-se que as fanpages foram usadas de forma mais intensa por candidatos que tiveram pouco retorno eleitoral, como é o caso do deputado federal Reginaldo Lopes (PT). Apesar da intensa utilização, o candidato não emplacou nas pesquisas e terminou com $7 \%$ dos votos válidos. Os candidatos que foram para o segundo turno - João Leite e Alexandre Kalil - usaram pouco as redes sociais, com um número muito reduzido de postagens. Isso revela que estamos num momento de transição, já que mídias digitais cada vez mais ganham espaço no cotidiano dos eleitores.

\section{Referências}

AGGIO, Camilo de Oliveira. Internet, Eleições e Participação: Questões-chave acerca da participação e do ativismo nos estudos em campanhas Online. In: GOMES, W.; MAIA, R.; MARQUES, F. J. (Orgs). Internet e Participação Política no Brasil. Porto Alegre: Editora Sulina, 2011. p. 175-196.

ALBUQUERQUE, Afonso de. 'Aqui você vê a verdade na tevê'. A propaganda política na televisão. 1999. 204 f. Dissertação (Mestrado em Comunicação, Imagem e Informação - MCII) - Universidade Federal Fluminense, Niterói, 1999.

BARDIN, Laurence. Análise de Conteúdo. Lisboa: Edições 70, 2010.

FIGUEIREDO, Marcus et al. Estratégias de Persuasão em Eleições Majoritárias. Uma proposta metodológica para o estudo da propaganda eleitoral. Opinião Pública, Campinas, v. 4, n. 3, p. 109-120, 1997.

GOMES, Wilson. Transformações da política na era da comunicação. 

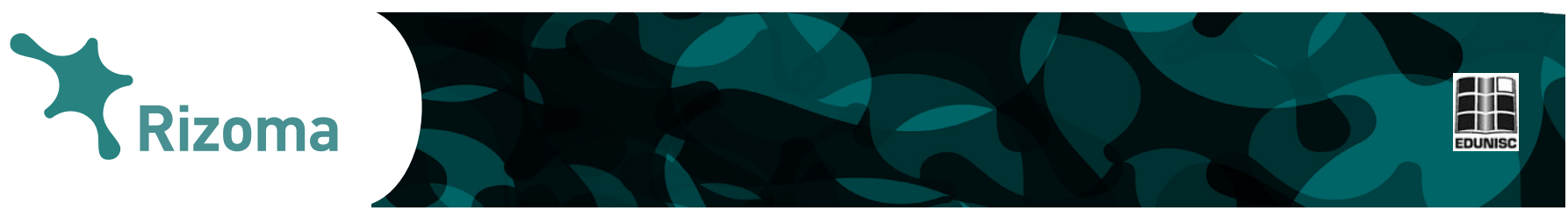

São Paulo: Paulus, 2004.

GOMES, Wilson. Participação política online: questões e hipóteses de trabalho. In: ; MAIA, R.; MARQUES, F. J. (Orgs). Internet e

Participação Política no Brasil. Porto Alegre: Editora Sulina, 2011.

MANIN, Bernard. As metamorfoses do governo representativo. Revista

Brasileira de Ciências Sociais (RBCS), São Paulo, ano 10, n. 29, out. 1995.

MIGUEL, L. F.; BIROLI, F. (Orgs.). Mídia, representação e democracia.

São Paulo: Editora Hucitec, 2010.

MARQUES, F. P. J.; SOUSA, I. J. Campanha negativa nas eleições de 2014: uma abordagem empírica sobre como os candidatos à Presidência da República utilizaram o Facebook. In: CERVI, Emerson Urizzi et al (Orgs). Internet e Eleições no Brasil. Curitiba: CPOP (Grupo de Pesquisa em Comunicação Política e Opinião Pública), 2016.

OLIVEIRA, L. A.; COIMBRA, M. Internet e eleições: as estratégias dos candidatos à Presidência em 2014 em suas fanpages. Verso e Reverso, São Leopoldo, v. 30, n. 75, p. 173-185, set./dez. 2016.

RECUERO, Raquel. Redes Sociais na Internet. Porto Alegre: Editora Sulina, 2009.

RODRIGUES, Adriano Duarte. Estratégias da Comunicação. Lisboa: Editorial Presença, 1990.

ROSSINI, P.; LEAL, P. R. F. Efeitos da campanha viral no universo das mídias sociais: o comportamento do eleitor no Twitter nas eleições 2010: o uso das redes sociais na campanha presidencial de Dilma Rousseff. Revista Compolítica, Rio de Janeiro, v. 1, n. 3, p.7-28, jan./jun. 2013, 